\title{
A STANDARD OPERATING PROCEDURE VIDEO FOR DAUNI SPA AND BEAUTY HOUSE TO STANDARDIZE ITS THERAPISTS' SERVICE QUALITIES
}

\author{
Sandria, D.Y. ${ }^{1}$ and Ibrahim, J.I. ${ }^{2}$ \\ 1,2 English Department, Faculty of Letters, Petra Christian University, Siwalankerto 121-131, Surabaya \\ 60236, East Java, INDONESIA \\ E-mail: yusisandria@yahoo.com; jusufib@petra.a.cid
}

\begin{abstract}
Dauni Spa, the company where I did my internship, provides spa treatment, sauna, and salon service. During my internship at Dauni Spa, I found there are various practices of massage techniques performed by the therapists that lead to inconsistency in the service qualities. This problem certainly resulted in unsatisfactory treatment because the customers would not be satisfied to receive inconsistent service quality. Aside from this problem, many newly-recruited therapists did not know the standard procedures of massage in Dauni Spa while they needed to start working very soon. Therefore, I intend to make a standard operating procedure (SOP) video as a solution to the problems. For the newly recruited therapists, the SOP video can give effective and efficient instructions of the standard procedures in Dauni Spa. For the old therapists, this video works as a standard service quality that should be put into practice by all therapists. The basic content of this video is the procedures of the massage and a little background information about Dauni Spa. From this video, there are some benefits that Dauni Spa can get. It can complete the written SOP that they have, cut down the cost of a trainer, and bring a good impact to the customers' satisfaction.
\end{abstract}

Keywords:Standard Operating Procedure, Service Quality, Training Video

\section{INTRODUCTION}

The company where I did my internship, Dauni Spa and Beauty House offers spa treatment, sauna, slimming treatment, and also salon service, including creambath, make up, manicure, and pedicure. During my internship, I found there were various practices of massage techniques performed by the therapists. When I asked two different therapists about the steps and techniques of full body massage, both of them told me different techniques and steps of the massage. When one of the therapists showed me the techniques of the massage that she usually does, the other therapists said that she was not correct since she still used the old techniques. All therapists should have used the new techniques which are the standard of the massage now. From this example, it can be concluded that there are at least two different techniques of massage used by the therapists, the old and new techniques. This problem certainly led to inconsistency in the service qualities given by the therapists. The inconsistency of the service qualities can cause unsatisfactory treatment because the customers would not be satisfied to receive inconsistent service quality.

In addition, many newly recruited therapists need to start working very soon but they do not know the standard procedures of doing treatment in Dauni Spa. These therapists at least have to know about the standard procedures in Dauni Spa so they can perform the treatment according to the standard. Although Dauni Spa has already had a written SOP, in the operations, it was not effective in giving information about the steps and techniques of the treatment since there were no supporting pictures in it. It was quite difficult for the therapists to have the same idea of the procedures and techniques of the treatment since there were only texts in the written SOP. The texts can be interpreted differently because there are no clear images of the steps and techniques of the treatment. Moreover, there were a lot of difficult terms and words in the written SOP which most of the therapists did not understand.

Based on the problems that I mentioned before, a standard operating procedure video would be the right solution to solve the problems. There are two purposes of this video. The first is to give effective and efficient training or instructions to the newly recruited therapists in doing a treatment. The second purpose is to standardize the service quality of the old therapists. By watching this video, 
the newly recruited therapists can learn the techniques of massage in Dauni Spa by themselves and can follow the right steps of the massage. On the other hand, this video also works as a reminder for the old therapists to maintain the service quality.

The purpose of making this product for Dauni Spa is to help the company to find the best solution to the problems that they have. This SOP video can be used as a measuring tool or benchmark to maintain the consistency of the service given by the therapists. If the therapists do not perform at least as good as the therapists in the video, it means they do not meet the standard of the company. From this video, I expect that therapists of Dauni Spa will perform better service so that all customers who come to Dauni Spa will be satisfied and eager to buy more or even inform their relatives about Dauni Spa.

There are three benefits that Dauni Spa can get through this SOP video. The first benefit is the company can cut down the cost of trainer. Dauni Spa management will not need to spend money for sending a trainer to visit each branch of Dauni Spa to explain or to train the therapists. Instead, they can just distribute the SOP video to the branches and make the therapists watch and learn from the video first. The second benefit is this SOP video will complete the written SOP that Dauni Spa has at this moment. This video works as a visual aid to the written SOP and helps the therapists to understand the procedures better. It is because it will not only tell the therapists of the steps or procedure of a treatment, but it will also show how to perform each steps of a treatment correctly and in detail. By the use of these moving pictures, it will help the therapists to understand the meaning of the difficult terms that they found on the written SOP. The third benefit is that it can bring a good impact to the customers' satisfaction since a high quality of service will satisfy the customers eventually. If all of the therapists perform as good as what is in the video, it will have a great influence to the customers' satisfaction. If the customers are happy with the services, they will visit Dauni Spa again and it means it can increase the sales of the company.

I used some information from online sources in designing and completing this project. According to Vicki A. Benge in eHow.com, A SOP should reach the point where unsupervised employee could perform the task quite well. Therefore, in making SOP, there are five important points, which are:

1. The tasks that need to be done

2. The step-by-step details of how to accomplish the tasks

3. The person who does the task

4. The materials and equipment needed to perform the work

5. The desired result

According to Isin Akyar (2012), a SOP should clarify the followings; the objective of SOP (Purpose), what are the uses of SOP (Scope), who will perform tasks (Responsible), who will make sure the implementation of procedure (Accountability), how tasks will be done (Procedure) (p. 371). Based on these two sources, it can be concluded that a SOP describes tasks that need to be accomplished by employees. It is followed by the purpose, the scope, the procedures of the task, the person who will perform the task, the materials and equipment required to do the task, the accountability of the implementation, and the end result should be.

According to Chris Anderson in bizmanualz.com, procedures consist of detailed descriptions which are compulsory and requiring the employees to perform a certain task. Therefore, procedures mostly use a lot of imperative sentences because they consist of tasks that should be followed. Based on the same source, it is written that tasks in procedures need to be written in active voice or direct style. The purpose is to make the readers know directly that the task is about them and to make them to do the task.

\section{PRODUCT AND RATIONALE}

There are some reasons why the standard operating procedure is made in the form of video. The first reason is because Dauni Spa is a business unit that sells services. Since services like massage and other spa treatments are intangible, the procedures might be quite complicated to be written or explained verbally. Hence, to make the newly recruited therapists understand the procedures better, one way of doing it is to make them visible through video or moving images. The moving images can also encourage the old therapists to perform as what is shown in the video. The 
second reason is that it is easier for the management of Dauni Spa to distribute the SOP to the branches. Since it is in the form of a CD, it is more practical and economical. One CD can reach to more than one therapist since the therapists can watch and learn from the video together, while a written SOP should be copied first as many as the number of therapists and distributed to each of them.

This video consists of steps and techniques of Deep Relax Massage or a full body massage. The reason why Deep Relax Massage is chosen to be in the video is because it is the base of massage in Dauni Spa. Dauni Spa has 4 kinds of massage treatment which are Deep Relax Massage, Warm Stone Massage, Ayurveda Massage, and Focus Massage. To be able to do other treatments, the therapists should know the techniques and steps of Deep Relax Massage since it is basic of these four treatments. Besides that, Deep Relax Massage is the most frequently purchased treatment among those four.

In the video, there is one therapist who performed the massage from the beginning until the end. There are two reasons why Dauni Spa management chose this therapist to be the model in the video. The first reason is that she had worked in Dauni Spa for more than one year so she is considered as one of the old therapists who used to handle customers. The second reason is because of the physical appearance of the therapist. Of all therapists that Dauni Spa has, this therapist is one of the youngest therapists for she is only 21 years old. She also wore some make up in the video to look good and professional. Since this video is going to be watched by a lot of people, it is important for Dauni Spa to show the best that they have.

The reason why I chose to give bit information, such as the history, the branches, the employees, and the number of workers in Dauni Spa in the opening of the video is because it can give the newly recruited therapists basic information about Dauni Spa. The therapists can have idea what kind of company Dauni Spa is and the meaning of the name Dauni. So, when the customers or other people ask about Dauni Spa, at least the therapists could give the right basic information. In this video, they can also see that Dauni Spa has already had more than eight branches spread across Java and has served more than 3000 customers in Surabaya although it was just established two years ago. As a new business, Dauni Spa also wants to attract as many good therapists as they can. This video could help Dauni Spa to show itself that it is a bright company that can give them promising career in the future if they want to build their career at Dauni Spa.

In the video opening, there are the purposes of the video and the purposes of the massage. The purposes of the video are placed in the opening of the video so the therapists will know immediately what video it is about and they can understand why they need to watch this video. The purposes of the massage are also placed in the opening of the video so the therapists can immediately know the massage that is going to be explained in the video. Also, it can work as a reminder to the therapists that the massage that they give could bring good effects to the customers.

The form of language which is used in this video is imperatives or commands, which begins with action verbs. Procedures use a lot of imperative sentences because they consist of tasks that should be done or followed. "Procedures are step-by-step descriptions that are not optional, they are imperative, as in commanding your worker to do something specific." (Anderson, C. 2013). Here, Dauni Spa management wants to give instructions or commands to the therapists to do those steps in the daily operations.

This SOP video mostly uses Indonesian language. The reason why this video mainly uses Indonesian language is because of the targeted audience of this video, which are the therapists. I noticed that most of them do not have ability in oral or written English. In one occasion, I noticed that the therapists had difficulty talking to the foreigners who came to have treatments. Therefore, I choose to not use English and use Indonesian language instead to help the therapists understand the techniques and procedures of the massage easily. I used a language which is the most familiar to them, which is Indonesian.

This video uses narration so the audience can hear the instructions and watch the techniques of the massage at the same time. The purpose is to emphasize the instructions of the treatment not only by visual but also by audio so the therapists cannot miss it.

The title of the background music of this video is Perspectives by Kevin Macleod. The music itself is a kind of soothing, relaxed, and calming music that is commonly used in spa house. The reason why this instrumental music is chosen to is because this kind of music is suitable for the type 
of business which is spa house. We often find the music in spa house is calming and relaxing so it can help the customers to take a good rest and to have a good feeling after the treatment. The other reason why this music is chosen to be the background music of the video is for the targeted audience who will watch this video later will also find it relaxing, not stressing, although they have to learn the techniques of massage from this video.

Although this video mainly uses Indonesian language, I still inserted English subtitles in it. There are three reasons why I decided to put English subtitles in the video. The first reason is due to the interest of the owner of Dauni Spa. This video can be used by her when presenting to the hotels' General Managers who are foreigners to show that Dauni Spa has already had standard procedures in its services. The second reason why I inserted English subtitles in the video is because this video will also be shared through YouTube. Dauni Spa management wants to let people know that Dauni Spa has already had standard procedures in doing the treatment. By uploading the SOP video to the YouTube, it means that this video is not only going to be watched by people who speak Indonesian, but there is a big possibility that it is going to be watched by people who do not speak Indonesian.

In the video closing, there is a logo of Dauni Spa, a logo of EBC, and Petra Christian University. The reason why there is a logo of Dauni Spa is because this video is made exclusively for Dauni Spa. I also put the logo of EBC and Petra Christian University in the end of the video in order to show that this project is made by a student of EBC of Petra Christian University.

\section{CONCLUSION AND SUGGESTIONS}

For my Business Communication Final Project, I decided to make a standard operating procedure video for Dauni Spa and Beauty House, the company where I did my internship. This SOP video is actually the solution to the problems that I found during my internship in Dauni Spa. I found that there were various practices of massage techniques performed by the therapists of Dauni Spa. Moreover, many newly recruited therapists do not know the standard procedures of doing treatment in Dauni Spa while they need to start working soon. The written SOP that Dauni Spa has is not effective to give information about the steps and techniques of the treatments since there were no clear images of the steps and techniques of the treatment. Therefore there are two purposes of the SOP video which are first, to give the effective and efficient training to the newly recruited therapists, second, to standardize the service qualities of the old therapists.

There are five parts in this SOP video, which are video opening, preparation before the massage, warm up session, massage process, and video closing. Those five parts of the video help Dauni Spa in giving information about the standard procedures of massage in Dauni Spa to all therapists. Aside from those five parts, there are some additional features in this video, such as Indonesian narration, English subtitles, and music background, which have their own purposes to make the audience understand the video better.

Finally, I hope that this SOP video can be used effectively by Dauni Spa management to solve the company's problems. It serves as the solution to the various practices problem in Dauni Spa. This video can be used as a benchmark of the procedures and service quality in Dauni Spa, so all therapists of Dauni Spa will always have to refer to this video while doing the massage. Besides, this video can help Dauni Spa to give effective and efficient trainings to the newly recruited therapists since they can directly learn the techniques of massage from the video by themselves. As a result, it can cut down the cost of hiring a trainer. They can just distribute the SOP video to the branches and make the therapists watch and learn from the video first. In addition, this video can also give a good impact to the customers' satisfaction.

For the next EBC students who choose to make a project, it is better if they can start discussing with the company people, where they are doing the internship, about the final project as soon as possible and asking whether they want to accept the project or not. The students also always have to make sure that the company is willing to pay for the project; otherwise, they will have to pay for the project using their own money. To make the company willing to pay for the project, the students have to be convincing an realistic in explaining the problems that the company has and how the product will indeed solve the problems. 


\section{REFERENCES}

Akyar, I. (2012). Standard Operating Procedures (What Are They Good For?).INTECH Open Access Publisher.

Anderson, C. (2013, July 11). How to Add Verb Power to Your Procedures. Retrieved January 11, 2017, from https://www.bizmanualz.com/write-better-procedures/how-to-add-verbpower-to-your-procedures.html

Benge, V.A. (2010, January 25). What Is the Purpose of an SOP? Retrieved January 11,2017, from http://www.ehow.com/facts_5916228_purpose-sop_.html 